\title{
Rapid identification of genome-edited mesenchymal stem cell colonies via Cas9
}

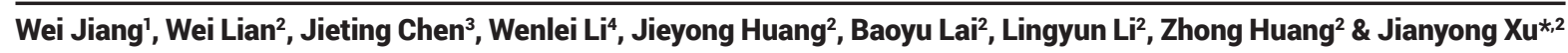

\section{ABSTRACT}

Mesenchymal stem cells (MSCs) have been intensively investigated and widely applied in regenerative medicine and immune modulation. However, their efficacy declines during the aging or disease process. Thus, genome-edited MSCs with overexpression or inhibition of specific genes hold a great deal of promise in terms of their therapeutic application. Here we optimized the direct PCR approach for rapid identification of genome-edited MSCs with only ten cells, which reduces the time and labor required to expand the MSC colonies. Combining with our previously optimized guide RNA structure and plasmid construction strategy for Cas9, we successfully identified MSC colonies overexpressing IL-10 in the AAVS1 locus.

\section{METHOD SUMMARY}

We optimized a direct PCR approach for rapid identification of genomeedited Mesenchymal stem cells (MSCs) with only ten cells, which reduces the time and labor required to expand MSC colonies.

\section{KEYWORDS:}

AAVS1 - Cas9 $\cdot$ direct PCR $\cdot$ genome editing $\cdot \mathrm{IL}-10 \cdot \mathrm{IL}-37 \cdot$ mesenchymal stem cells $\cdot \mathrm{MSC} \cdot \mathrm{MSC}$ colony $\cdot$ rapid identification

'Department of Anatomy, Histology \& Developmental Biology, School of Basic Medical Sciences, Shenzhen University Health Science Centre, Shenzhen, P.R. China; ${ }^{2}$ Department of Immunology, School of Medicine, Shenzhen University, Shenzhen, P.R. China; ${ }^{3}$ Department of Obstetrics, People's Hospital of Baoan, Shenzhen, P.R. China; ${ }^{4}$ Department of Obstetrics, Women \& Children Health Institute of Futian, Shenzhen, P.R. China; *Author for correspondence: xujianyong@szu.edu.cn

BioTechniques 66: 231-234 (May 2019) 10.2144/btn-2018-0183
Mesenchymal stem cells (MSCs) have multipotent (chondrocyte, osteoblast and adipocyte) and self-renewal abilities [1,2]. They have been proposed as an effective and safe cell source for stem cell therapy, with low immunogenicity and without major ethical concerns [3]. However, their efficacy declines during the aging or disease process [2,4]. Thus, genome-edited MSCs with overexpression or inhibition of specific genes hold great promise for therapeutic application.

Normally, it is necessary to expand a single cell colony to reach a sufficient cell number for DNA extraction after genome editing, which is both time- and laborintensive. Thus, the development and optimization of a direct cell lysis and PCR approach is necessary for rapid characterization of genome-edited MSC colonies with low cell number. Indeed, the direct cell lysis and PCR approach has been widely applied in many fields for rapid DNA characterization [5-15]. However, its application in characterizing genome-edited MSCs has not been demonstrated.

In the current study, we first compared different approaches of direct cell lysis and PCR analysis. We found that lysis buffer containing Tween 20 and proteinase $K(P K)$ was the most efficient approach to release DNA from only ten cells, which was sensitive enough for PCR detection. Previously, we had identified one optimized guide RNA structure with higher genomeediting efficiency and established one more efficient plasmid construction strategy for Cas9-gRNA [16,17]. Then we combined these techniques together to insert the immune suppressive gene IL-10 in the AAVS1 site, the safe harbor locus of human genome $[18,19]$.

\section{MATERIALS \& METHODS}

\section{Cell culture}

Human MSCs were isolated from umbilical cord. The umbilical cords were collected 10 min after the birth and informed consents were obtained. The umbilical cords were stored in DMEM/high glucose (Gibco, USA) with antibiotics (500 units/ml of penicillin and $500 \mu \mathrm{g} / \mathrm{ml}$ of streptomycin) on ice and delivered to the lab. Cell isolation should be performed within $8 \mathrm{~h}$. The umbilical cords were minced into $1-3 \mathrm{~mm}^{3}$ fragments and incubated in $1 \mathrm{mg} / \mathrm{ml}$ collagenase $B$ (STEMCELL Technologies, diluted in DMEM/ high glucose) for $12 \mathrm{~h}$ at $37^{\circ} \mathrm{C}$. Then, the isolated single cells were expanded in DMEM/high glucose (Gibco, USA) plus 5\% platelet lysate (Sigma), $2 \mathrm{U} / \mathrm{ml}$ heparin, and antibiotics (100 units/ml of penicillin and $100 \mu \mathrm{g} / \mathrm{ml}$ of streptomycin). The human MSCs were passaged with $0.05 \%$ TrypsinEDTA (Thermo Scientific). The MSCs were characterized with flow cytometry (CD90FITC mouse anti-human, BD Biosciences 555595; CD73-FITC mouse anti-human, BD Biosciences 561254; CD105-FITC mouse anti-human, BD Biosciences 561443; HLADR-PE mouse anti-human, BD Biosciences 562304; CD45-PE mouse anti-human, BD Biosciences 555483; CD34-PE mouse anti-human, BD Biosciences 550761; CD19-PE mouse anti-human, BD Biosciences 555413;CD11b-PE mouse anti-human, BD Biosciences 555388). The Differentiation was performed with the StemPro ${ }^{\circledR}$ Chondrogenesis Differentiation Kit (Gibco), StemPro Adipogenesis Differentiation Kit (Gibco), and StemPro Osteogenesis Differentiation Kit (Gibco).

\section{Direct cell lysis \& PCR}

12 different direct cell lysis methods were compared. The procedures were presented below:

(I) Direct lysis method: the cells were suspended in $15 \mu \mathrm{l}$ PBS and incubated at $95^{\circ} \mathrm{C}$ for $15 \mathrm{~min}$; the supernatant was used for PCR directly after centrifugation at 12,000 rpm for $1 \mathrm{~min}$.

(II) PK method: this method was performed as described before with modifications [12,14]. Briefly, the cells were suspended in $15 \mu$ l lysis buffer (10 mM Tris-HCl pH 8.0, 2 mM EDTA pH D 


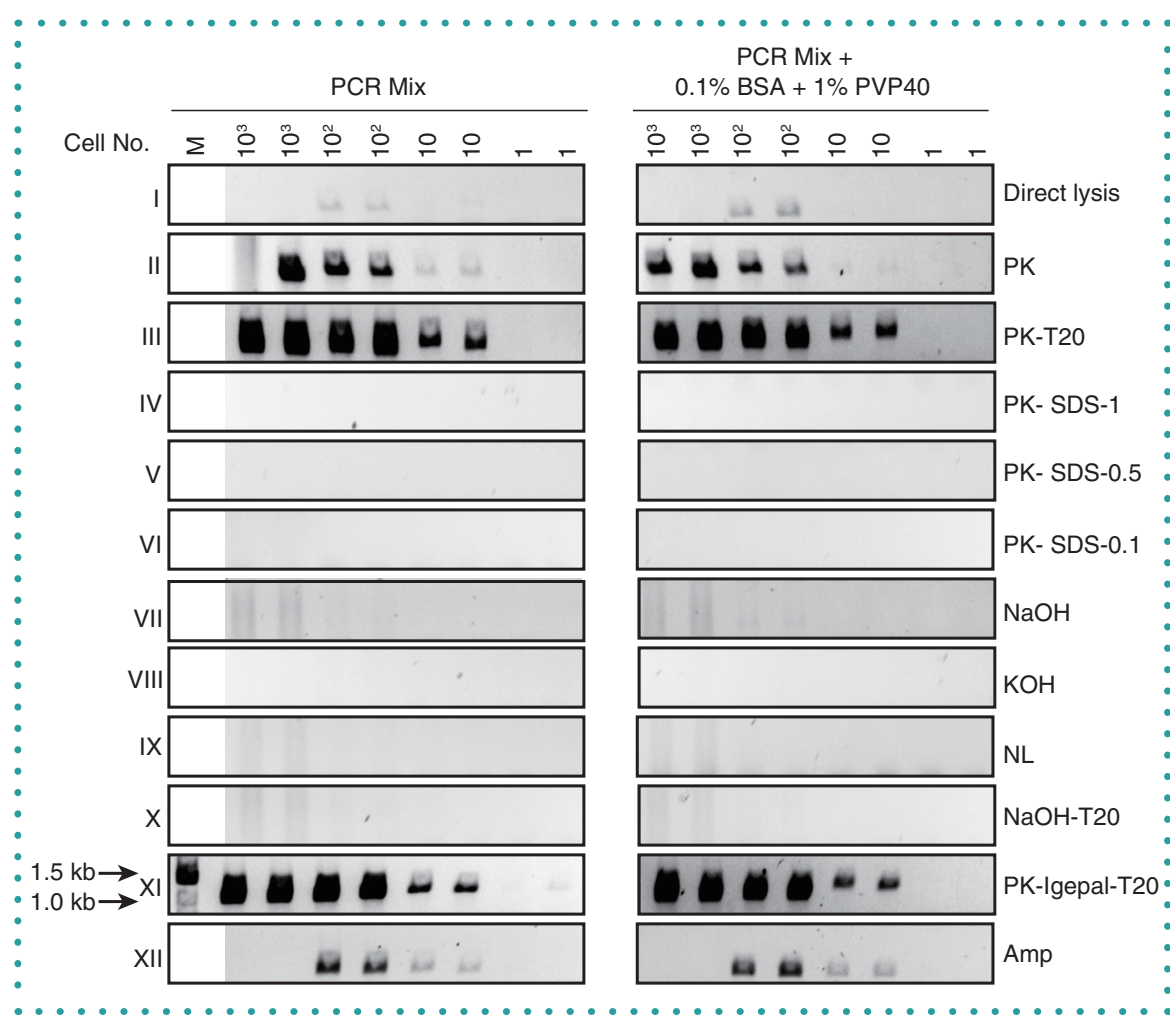

Figure 1. Methods comparison of direct cell lysis and PCR. Mesenchymal stem cells were plated onto a p96 plate with $1,10,10^{2}$ and $10^{3}$ cells per well. After overnight incubation, cells were directly lysed with the indicated cell lysis methods. I: direct lysis method; II: PK method; III: PK-T20 method; IV: PK- SDS-1 method; V: PK- SDS-0.5 method; VI: PK- SDS-0.1 method; VII: NaOH method; VIII: $\mathrm{KOH}$ method; IX: NL method; X: NaOH-T20 method; XI: PK-Igepal-T20 method; XII: Amp (Extract-N-Amp Blood PCR Kits) method. PCR was performed with $2 \times$ PCR mix (Thermo Scientific) with or without $0.1 \%$ BSA and $1 \%$ PVP40.

M: DNA ladder; arrows show DNA size with 1.0 or $1.5 \mathrm{~kb}$.

8.0, $0.2 \mathrm{M} \mathrm{NaCl}$ and $1 \mathrm{mg} / \mathrm{ml}$ proteinase $\mathrm{K})$, followed by $55^{\circ} \mathrm{C}$ for $60 \mathrm{~min}$ and then $95^{\circ} \mathrm{C}$ for $15 \mathrm{~min}$; the supernatant was used for PCR directly after centrifugation at 12,000 rpm for $1 \mathrm{~min}$.

(III) PK-T20 (Proteinase K-Tween 20) method: this method was performed as described before with modifications [11]. Briefly, the cells were suspended in $15 \mu$ l lysis buffer (10 mM Tris-HCl pH8.0, 2 mM EDTA pH $8.0,2 \%$ Tween 20 , and $1 \mathrm{mg} / \mathrm{ml}$ proteinase $\mathrm{K}$ ), followed by $55^{\circ} \mathrm{C}$ for $60 \mathrm{~min}$ and then $95^{\circ} \mathrm{C}$ for $15 \mathrm{~min}$; the supernatant was used for PCR directly after centrifugation at 12,000 rpm for $1 \mathrm{~min}$.

(IV) PK-SDS-1 (Proteinase K-SDS 1\%) method: this method was performed as described before with modifications [6]. Briefly, the cells were suspended in $15 \mu \mathrm{l}$ lysis buffer ( $1 \%$ SDS + $1 \mathrm{mg} / \mathrm{ml} \mathrm{PK}, 5 \%$ Tween 20, 5\% NP-40, 0.1\% BSA and 1\% PVP 40), followed by $55^{\circ} \mathrm{C} 60 \mathrm{~min}$ and then $95^{\circ} \mathrm{C}$ $15 \mathrm{~min}$; the supernatant was used for PCR directly after centrifugation at 12,000 rpm for $1 \mathrm{~min}$.

(V) PK-SDS-0.5 (Proteinase K-SDS 0.5\%) method: the cells were suspended in $15 \mu \mathrm{l}$ lysis buffer $(0.5 \%$ SDS $+1 \mathrm{mg} / \mathrm{ml} \mathrm{PK}, 5 \%$ Tween 20, 5\% NP-40, 0.1\% BSA and 1\% PVP 40), followed by $55^{\circ} \mathrm{C}$ for $60 \mathrm{~min}$ and then $95^{\circ} \mathrm{C}$ for $15 \mathrm{~min}$; the supernatant was used for PCR directly after centrifugation at 12,000 rpm for $1 \mathrm{~min}$.

(VI) PK-SDS-0.1 (Proteinase K-SDS $0.1 \%)$ method: the cells were suspended in $15 \mu$ l lysis buffer $(0.1 \%$ SDS +1 mg/ml PK, $5 \%$ Tween $20,5 \%$ NP-40, 0.1\% BSA and $1 \%$ PVP 40), followed by $55^{\circ} \mathrm{C}$ for $60 \mathrm{~min}$ and then $95^{\circ} \mathrm{C}$ for $15 \mathrm{~min}$; the supernatant was used for PCR directly after centrifugation at 12,000 rpm for $1 \mathrm{~min}$.

(VII) $\mathrm{NaOH}$ method: this method was performed as described before with modifications $[10,15]$. Briefly, the cells were suspended in $10 \mu \mathrm{l} 50 \mathrm{mM} \mathrm{NaOH}$, followed by $95^{\circ} \mathrm{C}$ for $10 \mathrm{~min}$ and neutralization by
$5 \mu \mathrm{l}(1 / 10$ volume) $1 \mathrm{M}$ Tris- $\mathrm{HCl} \mathrm{pH} 8.0$; the supernatant was used for PCR directly after centrifugation at 12,000 rpm for $1 \mathrm{~min}$.

(VIII) $\mathrm{KOH}$ method: this method was performed as described before with modifications $[5,7]$. Briefly, the cells were suspended in $10 \mu$ l lysis buffer $(200 \mathrm{mM} \mathrm{KOH}$, $50 \mathrm{mM} \mathrm{DTT}$ ), followed by incubation at $65^{\circ} \mathrm{C}$ for $10 \mathrm{~min}$ and neutralization by $5 \mu \mathrm{l}$ neutralization buffer $(300 \mathrm{mM} \mathrm{KCl}, 900 \mathrm{mM}$ Tris- $\mathrm{HCl}$ $\mathrm{pH}$ 8.3, $200 \mathrm{mM} \mathrm{HCl}$ ); the supernatant was used for PCR directly after centrifugation at 12,000 rpm for $1 \mathrm{~min}$.

(IX) NL ( $N$-Lauroylsarcosine salt) method: this method was performed as described before with modifications [13]. Briefly, the cells were suspended in $15 \mu \mathrm{l}$ lysis buffer $(3 \mu \mathrm{l} \mathrm{H} 20,3 \mu \mathrm{l} 250 \mathrm{ng} / \mu \mathrm{l}$ polyadenylic acid, $3 \mu \mathrm{l} 10 \mathrm{mM}$ EDTA, $3 \mu \mathrm{l} 250 \mathrm{mM}$ DTT, $3 \mu \mathrm{l} 0.5 \% N$-Lauroylsarcosine salt solution); followed by incubation at $95^{\circ} \mathrm{C}$ for $10 \mathrm{~min}$; the supernatant was used for PCR directly after centrifugation at 12,000 rpm for $1 \mathrm{~min}$.

(X) $\mathrm{NaOH}-\mathrm{T} 20$ ( $\mathrm{NaOH}-T w e e n ~ 20)$ method: the cells were suspended in $10 \mu \mathrm{l}$ lysis (100 $\mathrm{mM} \mathrm{NaOH}$ and $2 \%$ Tween 20); followed by incubation at $95^{\circ} \mathrm{C}$ for $10 \mathrm{~min}$ and neutralizating by $5 \mu$ neutralization buffer $(100 \mathrm{mM}$ Tris- $\mathrm{HCl}, 2 \mathrm{mM}$ EDTA); the supernatant was used for PCR directly after centrifugation at 12,000 rpm for $1 \mathrm{~min}$.

(XI) PK-Igepal-T20 (Proteinase K-IgepalTween 20) method: this method was performed as described before with modifications [8]. Briefly, the cells were suspended in $15 \mu$ l lysis buffer (10 mM Tris-HCl pH8.0, 2 mM EDTA pH 8.0, 1\% Tween 20, 1\% Igepal and $1 \mathrm{mg} / \mathrm{ml}$ proteinase $\mathrm{K}$ ), followed by $55^{\circ} \mathrm{C}$ for $60 \mathrm{~min}$ and then $95^{\circ} \mathrm{C}$ for $15 \mathrm{~min}$; the supernatant was used for PCR directly after centrifugation at 12,000 rpm for $1 \mathrm{~min}$.

(XII) Amp (Extract-N-Amp"' Blood PCR Kits) method: the cells were lyzed according to the manufacturer's instructions (Sigma).

PCR was performed in a total volume of $25 \mu$ l containing 2x PCR Master Mix (Thermo Scientific), $10 \mu \mathrm{M}$ forward and reverse primers, and $12 \mu \mathrm{l}$ cell lysis solution obtained from the above methods. Primers were used for amplifying one $1106 \mathrm{bp}$ fragment from the AASV1 site. Forward: 5'-CCCAACCCCATGCCGTCTTCACTCG-3' and reverse: 5'-CTAGGACGCACCATTCTCACAAAGG-3'. 40 PCR cycles were performed. 


\section{Gene targeting}

The donor plasmid was purchased from SBI (System Biosciences). Human IL-10 was PCR amplified and cloned into the donor plasmid according to the manufacturer's instructions. The gRNA target sequence (5'-GGGGCCACTAGGACAGGAT-3') was cloned into our Cas9-gRNA system as described before $[16,17]$. Plasmids were purified by PureYield"' Plasmid Maxiprep System (Promega). $1 \mu \mathrm{g}$ donor plasmid, plus $500 \mathrm{ng}$ gRNA plasmid and 500 ng hCas 9 plasmid were mixed with $2 \mu$ l Lipofactamine 3000 (Thermo Scientific) to transfect $20 \times 10^{4}$ human MSCs/well in a p6 plate. $48 \mathrm{~h}$ later, cells were trypsinized and diluted into 0.5 cells per well in a p96 plate after neutralization with MSC culture medium. 2 weeks later, cells were directly lysed with the optimized method and characterized with PCR according to the manufacturer's instruction (SBI, System Biosciences). The IL-10 protein secretion was validated by human IL-10 Quantikine ELISA Kit (D1000B, R\&D Systems).

\section{Real-time PCR}

RNA extraction and real-time PCR were performed as described previously [20]. The primers used for amplifying the IL-10 were: forward 5'-GCC TAA CAT GCT TCG AGA TC-3'; reverse 5'-TGA TGT CTG GGT CTT GGT TC-3' [21]; IL-37: forward 5'-TCA GCT GAA GAA GGA GAA ACT G-3'; reverse 5'-TTA TCT GTC ACC CCA ACA GG-3' [22].

\section{RESULTS \& DISCUSSION}

To determine the most efficient approach for direct cell lysis and PCR characterization of the genome-edited MSCs, a total of 12 different methods were compared using the wildtype MSCs, including previously demonstrated methods [5-15] and some modified methods. The MSCs were firstly plated onto a p96 plate with 1, 10, $10^{2}$ and $10^{3}$ cells per well. After overnight incubation, cells were directly lysed with the indicated cell lysis methods. One 1106 bp DNA fragment amplified by PCR was used to assess the efficiency of DNA release from a different number of MSCs. PCR was performed with 2 x PCR mix (Thermo Scientific) with or without $0.1 \%$ BSA and $1 \%$ PVP40, which could enhance the PCR efficiency and release polymerase inhibition. Data showed that the method III

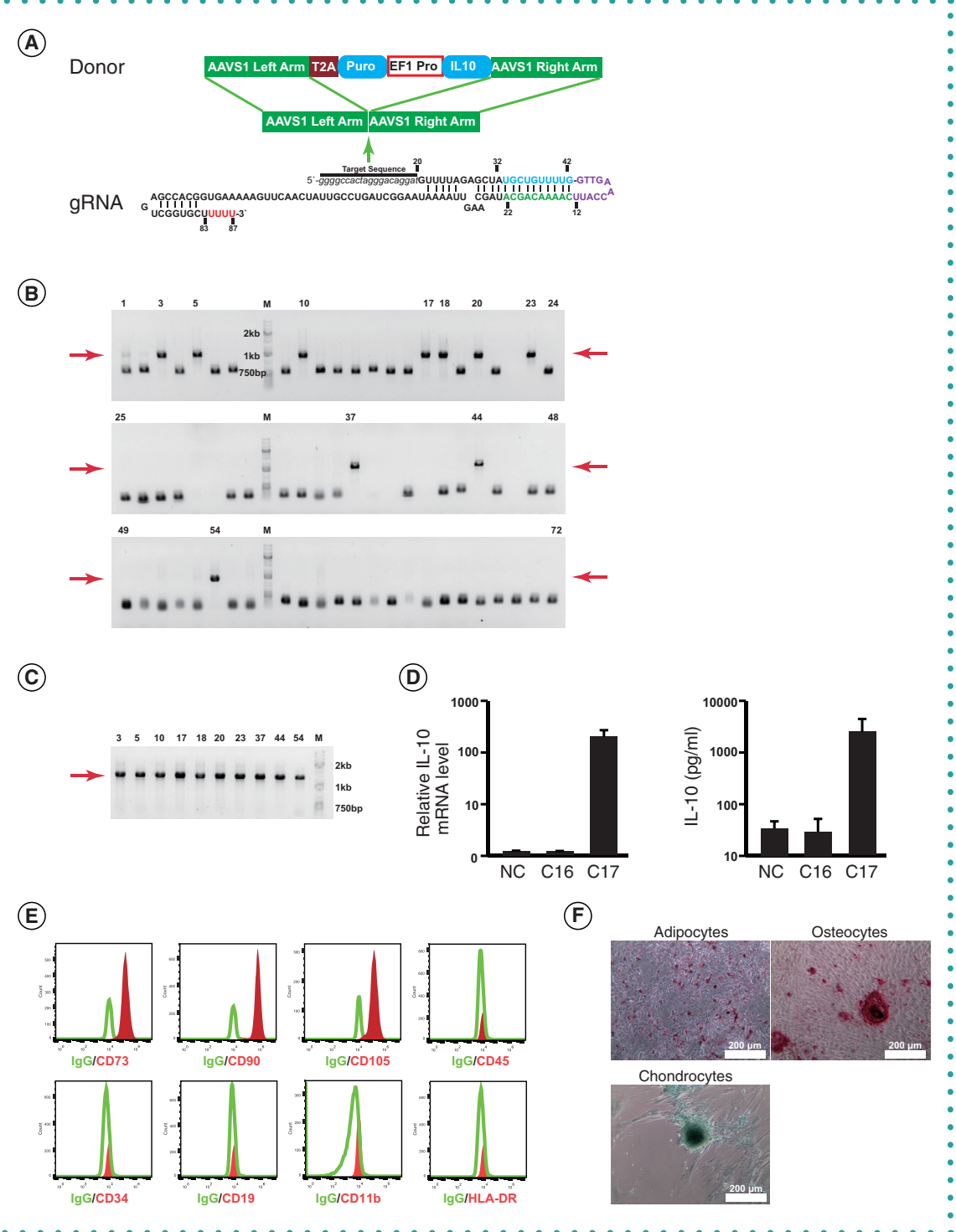

Figure 2. Target inserting the IL-10 into AASV1 site. (A) Donor and gRNA structures. (B) PCR characterization of genome-edited mesenchymal stem cell (MSC) colonies by amplifying the left arm. Arrow shows the predicted PCR product size. (C) PCR characterization of genome-edited MSC colonies by amplifying the right arm. Arrow shows the predicted PCR product size. (D) mRNA and protein levels of IL-10 among the colony 16 (C16) without donor insertion, colony 17 (C17) with correct insertion, and the wild-type of MSCs (NC). (E) MSC colony $\mathrm{C} 17$ was characterized with MSC markers by flow cytometry. (F) MSC colony $\mathrm{C} 17$ could differentiate into adipocytes, osteocytes and chondrocytes.

M: DNA ladder; arrows show DNA size with $750 \mathrm{bp}, 1.0$ or $2 \mathrm{~kb}$.

(PK-T20) and XI (PK-Igepal-T20) were the most efficient approaches, successfully amplifying the target DNA fragments from only ten cells (Figure 1). Furthermore, the DNA fragment could be successfully amplified from 10 to $10^{3}$ cells, making them suitable for both low and high cell number (Figure 1), as the proliferation ability may differ from different MSC colonies. However, the BSA and PVP40 addition did not improve efficiency.
Method III (PK-T20) was applied to characterize the MSC colonies by correctly inserting IL-10 into the AASV1 site via Cas9. IL-10 is an important anti-inflammatory factor with immune suppressive functions [23,24]. Although MSCs have been widely studied to treat autoimmune diseases, such as systemic lupus erythematosus [2]. Their therapeutic efficacy should be enhanced with overexpression of the immune suppressor IL-10. Thus, we 
- have tried to introduce IL-10 to the human genome safe harbor AASV1 site [19]. The gRNA structure and Cas 9 system have been demonstrated before (Figure 2A) [16,17]. The donor structure and target sequence were obtained from SBI (Figure 2A). Data showed that method III (PK-T20) could successfully identify the colonies characterized with left-arm PCR (Figure 2B). And this was further confirmed with right-arm PCR (Figure 2C). Then, the mRNA level of IL-10 was measured by real-time PCR among the colony 16 (C16) without donor insertion, colony 17 (C17) with correct insertion, and the wildtype MSCs. Data showed that the mRNA and protein levels of IL-10 in C17 were much higher than the wildtype and $\mathrm{C} 16$ (Figure 2D). The genome editing procedures have not affected the phenotype of the MSC, including the cell surface marker expression (Figure 2E) and differentiation abilities (Figure 2F), which was also confirmed prior to genome editing (Supplementary Figure 1). Furthermore, this was also validated by inserting another immune suppressor gene, IL-37, into the same locus [25] (Supplementary Figure 2).

We demonstrated here that the PK-T20 method could be used for characterizing MSC colonies with cell number ranging from 10 to 1000 . By using this method, we have successfully established a MSC colony overexpressing IL-10 or IL-37 expression in the AASV1 site, which might hold big promises for therapeutic applications in the future.

\section{AUTHOR CONTRIBUTIONS}

Wei Jiang, flow cytometry analysis; Wei Lian, cell culture and PCR analysis; Jieting Chen, MSC isolation; Wenlei Li, MSC isolation; Jieyong Huang, PCR characterization; Baoyu Lai, PCR characterization; Lingyun Li, plasmid construction; Zhong Huang, qPCR and ELISA; Jianyong Xu, Gene targeting and MSC differentiation; project design and manuscript preparation
FINANCIAL \& COMPETING INTERESTS DISCLOSURE

This work was supported by Natural Science Foundation of Shenzhen (JCYJ20170302 152735071, JCYJ201708 18093720089), Natural Science Foundation of SZU (2017083, 2017082), and Medical Foundation of Guangdong (A2018308). The authors have no other relevant affiliations or financial involvement with any organization or entity with a financial interest in or financial conflict with the subject matter or materials discussed in the manuscript apart from those disclosed.

No writing assistance was utilized in the production of this manuscript.

\section{OPEN ACCESS}

This work is licensed under the AttributionNonCommercial-NoDerivatives 4.0 Unported License. To view a copy of this license, visit http://creativecommons.org/licenses/ by-nc-nd/4.0/

\section{SUPPLEMENTARY DATA}

To view the supplementary data that accompany this paper please visit the journal website at: www.future-science. com/doi/suppl/10.2144/btn-2018-0183

\section{REFERENCES}

1. Pittenger MF, Mackay AM, Beck SC et al. Multilineage potential of adult human mesenchymal stem cells. Science 284(5411), 143-147 (1999).

2. Xu J. Therapeutic applications of mesenchymal stem cells for systemic lupus erythematosus. Adv. Exp. Med. Biol. doi:10.1007/5584_2018_212 (2018).

3. Wang Y, Chen X, Cao W, Shi Y. Plasticity of mesenchymal stem cells in immunomodulation: pathological and therapeutic implications. Nat. Immunol. 15(11) 1009-1016 (2014)

4. Asumda FZ. Age-associated changes in the ecologica niche: implications for mesenchymal stem cell aging. Stem Cell Res. Ther. 4(3), 47 (2013).

5. Burlet P, Frydman N, Gigarel N et al. Improved single-cell protocol for preimplantation genetic diagnosis of spinal muscular atrophy. Fertil. Steril. 84(3), 734-739 (2005).

6. Cui X, Li H. Determination of gene organization in individual haplotypes by analyzing single DNA fragments from single spermatozoa. Proc. Natl Acad. Sci. USA 95(18), 10791-10796 (1998).

7. Cui XF, Li HH, Goradia TM et al. Single-sperm typing determination of genetic distance between the $\mathrm{G}$ gam ma-globin and parathyroid hormone loci by using the ma-globin and parathyroid hormone loci by using the
polymerase chain reaction and allele-specific oligomers.
Proc. Natl Acad. Sci. USA 86(23), 9389-9393 (1989).

8. Geigl JB, Speicher MR. Single-cell isolation from cell suspensions and whole genome amplification from single cells to provide templates for $\mathrm{CGH}$ analysis. Nat. Protoc. 2(12), 3173-3184 (2007).

9. Kim SA, Yoon JA, Kang MJ, Choi YM, Chae SJ, Moon SY An efficient and reliable DNA extraction method for preimplantation genetic diagnosis: a comparison of allele drop out and amplification rates using different sing cell lysis methods. Fertil. Steril. 92(2), 814-818 (2009).

10. Meeker ND, Hutchinson SA, Ho L, Trede NS. Method for isolation of PCR-ready genomic DNA from zebrafish tissues. Biotechniques 43(5), 610, 612, 614 (2007).

11. Meredith M, Bright JA, Cockerton S, Vintiner S. Development of a one-tube extraction and amplification method for DNA analysis of sperm and epithelial cells recovered from forensic samples by laser microdissection. Forensic Sci. Int. Genet. 6(1), 91-96 (2012).

12. Minucci A, Gentile L, Zuppi C, Giardina B, Capoluongo E. Rapid and simple identification of the commonest glucose-6-phosphate dehydrogenase (G6PD) Italian mutations: from DNA extraction to genotyping. Clin. Chim Acta 413(11-12), 1018-1019 (2012).

13. Tsuchiya $\mathrm{S}$, Sueoka $\mathrm{K}$, Matsuda $\mathrm{N}$ et al. The 'spanning protocol': a new DNA extraction method for efficient single-cell genetic diagnosis. J. Assist Reprod. Genet. 22(11-12), 407-414 (2005)

14. Van Der Burg M, Kreyenberg $\mathrm{H}$, Willasch $\mathrm{A}$ et al. Stand ardization of DNA isolation from low cell numbers for chimerism analysis by PCR of short tandem repeats. Leukemia 25(9), 1467-1470 (2011).

15. Xin Z, Velten JP, Oliver MJ, Burke JJ. High-throughput DNA extraction method suitable for PCR. Biotechniques 34(4), 820-824, 826 (2003).

16. Xu J, Li W, Hossen MM, Jia Y, Li L, Huang Z. Optimized plasmid construction strategy for Cas9. Cell Physiol. Biochem. 48(1), 131-137 (2018).

17. Xu J, Lian W, Jia Y, Li L, Huang Z. Optimized guide RNA structure for genome editing via Cas9. Oncotarget 8(55), 94166-94171 (2017)

18. De Ravin SS, Reik A, Liu PQ et al. Targeted gene addition in human CD34(+) hematopoietic cells for correction of $X$-linked chronic granulomatous disease. Nat. Biotechnol. 34(4), 424-429 (2016).

19. Sadelain M, Papapetrou EP, Bushman FD. Safe harbours for the integration of new DNA in the human genome. Nat. Rev. Cancer 12(1), 51-58 (2011).

20. Xu JY, Lee YK, Ran X et al. Generation of Induced cardiospheres via reprogramming of skin fibroblasts for myocardial regeneration. Stem Cells doi:10.1002/ stem.2438 (2016).

21. Staples KJ, Smallie T, Williams LM et al. IL-10 induces IL-10 in primary human monocyte-derived macrophages via the transcription factor Stat3. J. Immunol. 178(8), 4779-4785 (2007)

22. Rudloff I, Cho SX, Lao JC et al. +Monocytes and dendritic cells are the primary sources of interleukin 37 in human immune cells. J. Leukoc. Biol. 101(4), 901-911 (2017).

23. Li MO, Flavell RA. Contextual regulation of inflamma tion: a duet by transforming growth factor-beta and interleukin-10. Immunity 28(4), 468-476 (2008).

24. Moore KW, O'garra A, De Waal Malefyt R, Vieira $P$, Mosmann TR. Interleukin-10. Annu. Rev. Immunol. 11, 165-190 (1993).

25. Nold MF, Nold-Petry CA, Zepp JA, Palmer BE, Bufler $P$, Dinarello CA. IL-37 is a fundamental inhibitor of innate immunity. Nat. Immunol. 11(11), 1014-1022 (2010). 